\title{
Erratum to: The protective effect of Borago Officinalis extract on amyloid $\beta(25-35)$-induced long term potentiation disruption in the dentate gyrus of male rats
}

\author{
Somayeh Zargooshnia • Siamak Shahidi • \\ Fatemeh Ghahremanitamadon - Ali Nikkhah • \\ Mehdi Mehdizadeh • Sara Soleimani Asl
}

Published online: 26 August 2014

(C) Springer Science+Business Media New York 2014

Erratum to: Metab Brain Dis (2014)

DOI 10.1007/s11011-014-9594-4

The original version of this article unfortunately contained a mistake. Schematic view of hippocampus that illustrates the place of stimulating and recording electrodes is from a published article (Karimi SA, 2013, DOI: 10.1016/j.brainres. 2013.09.029) and reprehensive sample traces of evoked field potential in the DG recorded prior to and $60 \mathrm{~min}$ after high frequency stimulation should refer to control, sham, beta amyloid, and borage groups, not to high fat diet, restricted high fat diet, and antioxidant groups. The correct Fig. 1 is presented here.

The online version of the original article can be found at http://dx.doi.org/ 10.1007/s11011-014-9594-4 .

S. Zargooshnia · S. Shahidi · F. Ghahremanitamadon · A. Nikkhah • S. Soleimani Asl

Neurophysiology Research Center, Hamadan University of Medical

Sciences, Hamadan, Iran

M. Mehdizadeh

Cellular and Molecular Research Center, Faculty of Advanced

Technologies in Medicine, Anatomy Department, Iran University of

Medical Sciences, Tehran, Iran

S. Soleimani Asl $(\triangle)$

Anatomy Department, School of Medicine, Hamadan University of

Medical Sciences, Hamadan, Iran

e-mail: s.soleimaniasl@umsha.ac.ir 
Fig. 1 Schematic view of hippocampus that illustrates the place of stimulating and recording electrodes (a). EPSP slope and PS amplitude in control group (b).

Reprehensive sample traces of evoked field potential in the DG recorded prior to and $60 \mathrm{~min}$ after high frequency stimulation in all groups (c)

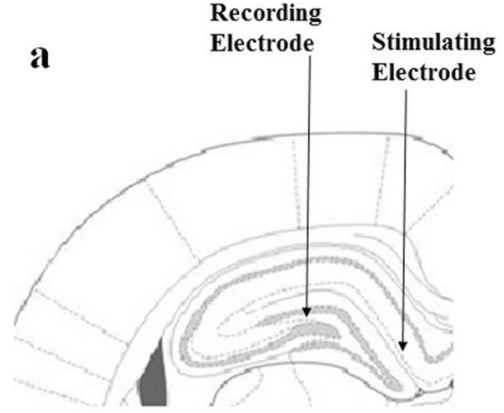

b

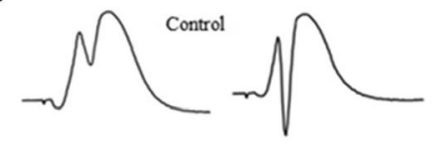

Before HFS c

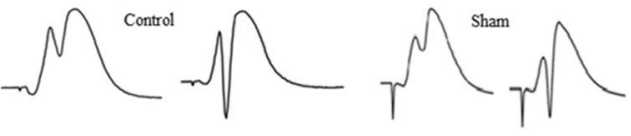

$\int_{-\infty}^{\text {A-beta }} \sqrt{ }$

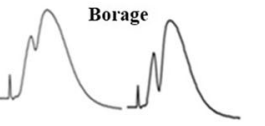

$\prod_{10 \mathrm{~ms}}^{500 \mathrm{mv}}$ 